ISSN e- 2594-1100

en-claves del pensamiento / núm. 30 / julio-diciembre / 2021 / e461

https://doi.org/10.46530/ecdp.v0i30.461 ARTÍ́CULOS

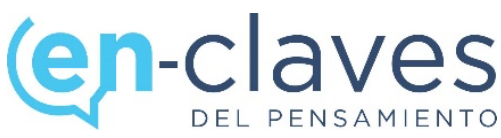

\title{
¿UNA NUEVA ESPECIE DE IDEAS? LAS “IDEOGLOBÍAS" COMO PROPUESTAS PARA UNA MEJOR CONVIVENCIA GLOBAL EN LA ÉPOCA CONTEMPORÁNEA: CONCEPTO Y CASOS ${ }^{1}$
}

\author{
A New Species of Ideas?: The "Ideoglobys" Like Proposals for a Better Global \\ Coexistence in Contemporary Society: Concept and Case Studies \\ Eduardo Devés Valdés, Universidad de Santiago de Chile, Chile \\ Correo electrónico: eduardo.deves@usach.cl
}

Recibido: 23/02/2021

Aceptado: $19 / 09 / 2021$

Publicado: 01/11/2021

\begin{abstract}
Resumen. Este trabajo se ocupa de la proliferación de ideas sobre asuntos mundiales que ofrecen específicamente propuestas para la mejor convivencia global, en una época de altísima circulación como la que vivimos a comienzos del siglo XXI. Para este tipo de ideas, de expresiones eidéticas, se propone la noción "ideoglobía" o, a secas, "globía". Luego, se elabora un conjunto de criterios que definen la noción, tanto como la distinguen de otras expresiones eidéticas, como las ideologías, los sistemas filosóficos, las "cotidianías" y los "pan-ismos", entre otras. Durante las últimas décadas han coexistido varias ideoglobías operantes: el "noeismo" (de NOEI, nuevo orden económico internacional), el "gobernancismo global" (de gobernanza global), el "neo-tianxiasmo" (del mandarín tianxia, "todo bajo el cielo") y, sobre todo, el "derecho-humanismo", que es el que más interesa en esta oportunidad, dado que al parecer es la que goza de mayor acogida a nivel mundial, permitiendo así mostrar cómo se constituye un caso de ideoglobía.
\end{abstract}

Palabras clave: "Ideoglobía" ideología, "derechohumanismo", "noeismo", "neo-tianxiaismo".

Abstract. This paper deals with the proliferation of ideas on global issues that specifically offer proposals for better global coexistence, at a time of very high circulation of ideas such as the circulation we lived at the beginning of the $21^{\text {st }}$ century. For these kind of ideas, of eidetic expressions, the notion of "ideogloby" or just "globy" is proposed. Then, a set of criteria defining the notion is elaborated, as much as they are distinguished from other eidetic expressions, such as ideologies, philosophical systems, "cotidianies" and "pan-isms", among others. Over the past few decades, several operative ideoglobies have co-existed: "nieoism" (from NIEO, the New International Economic Order), "global governance", "neo-tianxianism" (from the Mandarin tianxia, "all under the sky"), and, above all, Human Rights Law, which is the one that interests us at this time, given that it appears to be the most widely welcomed worldwide.

Keywords: "Ideogloby", ideology, "humanrightism", "noeism", "neo-tianxiaism”.

Cómo citar: Devés, E. (2021). ¿Una nueva especie de ideas? Las "ideoglobías" como propuestas para una mejor convivencia global en la época contemporánea: concepto y casos. EN-CLAVES del pensamiento, O(30), e461. doi: https://doi.org/10.46530/ecdp.v0i30.461

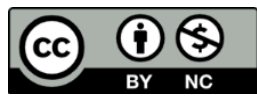

Esta obra está protegida bajo una Licencia

Creative Commons Atribución - No comercial

4.0 Internacional

\footnotetext{
${ }^{1}$ Una versión anterior de este trabajo fue presentada en la XV reunión de El Corredor de las Ideas, Bahía Blanca, Argentina. Agradezco los aportes de Christian Álvarez y Juan Pablo Venables. Vayan también mis agradecimientos a quienes han trabajado como dobleciegos, por las sugerencias que seguramente harán este abigarrado texto algo mejor y más fácil de digerir. En especial a quien sugirió al autor de estas páginas que se explicitara la deuda que mostraba su trabajo con las elaboraciones de Eduardo Devés. Esto contribuye a mostrar la validez del sistema dobleciego.
}

www.enclavesdelpensamiento.mx

https://doi.org/10.46530/ecdp.v0i30.461 


\section{Formulación del problema: especificaciones conceptuales}

El aumento de la conciencia planetaria, propiciado por la globalización de problemas como enfermedades, crisis climáticas, seguridad, entre otros, tiene un correlato en la proliferación de ideas sobre asuntos mundiales, potenciando así formas de pensamiento, nuevas o renovadas, que ofrecen específicamente propuestas para la mejor convivencia global, en una época de altísima circulación como la que vivimos. Para este tipo de expresiones eidéticas, se propone la noción "ideoglobía” o, a secas, "globía".

En el terreno global, vienen tomando forma entidades eidéticas específicas que tienen muy poco sentido en el ámbito de las polis particulares, especialmente en las pequeñas, donde se piensa escasamente de manera global, pues las posibilidades de incidencia son demasiado bajas. Se trabaja la noción "ideoglobía", distinguiéndola y emparentándola con otras entidades eidéticas como "ideología" o "cosmovisión”, e intentando entenderlas en los tipos de sociedades-épocas y ámbitos en que estas han operado. Las ideoglobías son entidades eidéticas que se han ido configurando en el quehacer de causas que parecen convocar a la humanidad e incluso a la vida, como conjunto. Ejemplos son, entre otras, el gobernancismo global, el noeismo (de NOEI, Nuevo Orden Económico, Internacional), el ambientalismo, el neo-tianxiasmo (todo bajo el cielo en mandarín), y el derecho-humanismo, el globalismo (o globalizacionismo). ${ }^{2}$ Las ideoglobías alcanzan identidad como tales en la medida que existen espacios globales de discusión, que resultan creíbles para múltiples agentes intelectuales. Es decir, las ideoglobías, por su propio carácter, convocan la existencia de plataformas globales sobre asuntos que hacen imaginar como globales, en cierto sentido, creando una "agenda global imaginada", en términos "prácticos", no necesariamente en términos ontológicos, como se entiende el concepto "universal-universalista".

Lo primero que debe señalarse es que se realiza actualmente ${ }^{3}$ una elaboración conceptual tendiente a clasificar y distinguir la diversidad de las entidades eidéticas, que

\footnotetext{
2 Acudo al sufijo “ismo" para acentuar el carácter de expresión eidética, como otros "ismos" frente a NOEI, gobernanza, derechos humanos o globalización que no son tendencias eidéticas ni ideoglobías, sino conceptos que aluden a nociones jurídicas o condiciones o mitologías, pero que se han constituido en cimientos, ejes o columnas vertebrales de algunas ideoglobías.

${ }^{3}$ Michael Freeden, Ideology: A Very Short Introduction (Oxford: Oxford University Press, 2003); Manfred B. Steger, "Political Ideologies and Social Imaginaries in the Global Age", Global justice: Theory practice
} 
frecuentemente se han manejado con nociones difusas y confusas, pretendiendo extraer conclusiones del estudio de unas para otras, como si fueran suficientemente similares. Estas confusiones derivan en buena medida de una falencia a nivel de las conceptualizaciones: lo que es válido para las cosmovisiones no lo es necesariamente para las ideologías, y la conceptualización utilizada para comprender paradigmas científicos no es simplemente traspasable al estudio de los sistemas filosóficos o las ideoglobías. Todo ello, sin menoscabo de la existencia de zonas grises, especialmente en situaciones de mutación y aparición de nuevas expresiones eidéticas. En este marco, una distinción tan básica como necesaria es la que se hace entre lo ideológico (relativo a las ideologías) de lo eidético (relativo a las ideas).

Las ideoglobías son expresiones eidéticas que se asumen con dimensión global, ofreciendo específicamente propuestas para la mejor convivencia en el mundo como totalidad, ${ }^{4}$ en una época de alta circulación y de altos niveles de gentecracia. ${ }^{5}$ Las ideoglobías suponen la posibilidad de causas globales, con destinatarios amplios y transfronterizos, que se expresan en diversas lenguas, donde existen canales planetarios de difusión, con estrategias de circulación internacional de las ideas, con la posibilidad de cierta coincidencia de muchas voces en torno valores, que se supone pueden-deben ser compartidos.

La hipótesis consiste en apuntar a que la noción ideoglobía es mejor que otras como "ideología", "filosofía política", "filosofía de la historia" o "pensamiento político" para conceptualizar la especificidad de este género de expresiones eidéticas contemporáneas que intentan pensar el mundo como un todo en vistas a una mejor convivencia global.

rhetoric, núm. 2 (2009): 1-17. https://doi.org/10.21248/gjn.2.0.13; Manfred B. Steger y Paul James (eds.), Globalization and Culture. Volume IV, Ideologies of Globalism (Londres: Sage, 2010); Eduardo Devés y Andrés Kozel, Estudios Eidéticos. Una conversación desde el sur, sobre la vida de las ideas y la reconfiguración de un espacio disciplinar (Santiago de Chile: Ariadna, 2018).

${ }^{4}$ A este respecto, debe tenerse en cuenta que la "totalidad como es concebida" es de acuerdo al imaginario que poseen las intelectualidades que participan de tales conversaciones: en este caso se trata de concebir a participantes desde muy diversos espacios geográficos, sectores sociales, géneros, etnias y lenguas, aunque asumiendo que no todos los seres humanos se encuentran participando, ni mucho menos en condiciones equivalentes.

5 Entiendo "gentecracia" como amplia y plural participación en discusiones públicas internacionales y globales, de agentes de muy diversas regiones (pertenencias, adscripciones y ocupaciones), cosa que conlleva la constitución progresiva de una opinión pública sobre asuntos mundiales. Véase Eduardo Devés, "Direitos humanos, sociedade civil e gentecracia na esfera mundial: pensando a partir do sul", en Daniel R Cenci y Gilmar Bedin (orgs.), Direitos humanos, relaçoes internacionais e medio ambiente (Curitiba: Multimedia, 2013). 
El objetivo del artículo consiste en elaborar el concepto "ideoglobía" para referirse a este conjunto de expresiones eidéticas que se ha venido constituyendo desde mediados del siglo XX, aunque con antecedentes de siglos y milenios. Más específicamente, el objetivo al proponer este concepto, consiste en dar respuesta a una situación en que nos encontramos ante la proliferación de propuestas meta-nacionales y globales, para las cuales carecemos de términos específicos para designarlas.

La metodología para avanzar hacia el objetivo contempla dos procedimientos, uno que opera a partir de la contrastación de este neologismo con otros conceptos como "ideología", "filosofía política", "filosofía de la historia" o "pensamiento político"; el segundo opera exponiendo varias de estas expresiones eidéticas (noeismo, gobernancismo global, neo-tianxiaismo, ambientalismo, derecho-humanismo), mostrando la posibilidad de adscribirlas en este concepto, mejor que en otros de los señalados.

Antes de entrar en materia, debe señalarse también que existe una larga trayectoria de intentos de clasificación ${ }^{6}$ de los diferentes géneros y subgéneros de expresiones eidéticas, una tarea que han emprendido los estudios filosóficos y la historia de las ideas. La proliferación de ecosistemas intelectuales letrados conlleva el desarrollo de nuevos géneros eidéticos que es necesario nombrar y estudiar en su especificidad, de modo parecido a como los estudios literarios no podrían tratar sin distinciones al epígrafe, el poema, el cuento y la novela, por ejemplo.

De hecho, así como se diversifican los tipos de actividad humana y los ecosistemas intelectuales, se van diferenciando tipos de entidades eidéticas, cuyas características no son atribuibles a todas las demás. Durante el siglo XIX, personas como Destutt de Tracy, MarX y Dilthey ${ }^{7}$ intentaron avanzar en este proceso de clasificación y distinción, careciendo de criterios claros y perteneciendo todavía a ecosistemas intelectuales poco diversificados, si se comparan a la información y desarrollo disciplinar de inicios del XXI, especialmente

\footnotetext{
${ }^{6}$ Los estudios eidéticos (estudios sobre las ideas) tienen entre muchas ocupaciones, definir y clasificar las entidades eidéticas que se han incubado y hospedado en ecosistemas intelectuales a lo largo de la historia, a la vez que ir sistematizando las nuevas formaciones en gestación en sus mutaciones simbióticas con las sociedades e incluso las que son producto del quehacer programado de las intelectualidades. A la hora de estudiar las entidades eidéticas que pretenden organizar el mundo contemporáneo hacia una vida mejor se hace necesario revisar, "estirar", reacomodar, re-definir o renovar categorías que van quedando obsoletas para pensar lo antes impensado y que se hace parcialmente impensable con las viejas categorías, que se revientan como los odres viejos. Devés y Kozel, Estudios eidéticos.

${ }^{7}$ Steger, "Political ideologies".
} 
teniendo en cuenta la nunca vista pluralidad eidética o eidodiversidad de las megalópolis. Durante el siglo XX y XXI se ha avanzado en este proceso, a partir de trabajos de Karl Mannheim, Thomas Kuhn, Mircea Eliade, Luis Althusser, ${ }^{8}$ entre muchas otras figuras. Sin olvidar que no cesan de renovarse los criterios de clasificación y tampoco terminan de aparecer, nominarse, descubrirse y reconceptualizarse géneros y subgéneros eidéticos, como ocurre con “cosmovisión”, "weltanschauung” y "visión del mundo", por ejemplo. 9

\section{Primer camino, contrastación con otros conceptos}

Este procedimiento consiste en constatar la existencia de un imaginario global, ${ }^{10}$ que facilita la constitución de expresiones eidéticas específicas, cuya detección puede hacerse más expedita cuando se ha desarrollado una destreza o un oficio para nombrar expresiones nuevas (diferentes o innovadoras) como ha ocurrido con los estudios eidéticos en América Latina. Debe insistirse en que se trata de elaborar un concepto específico respecto de expresiones eidéticas orientadas hacia la mejor convivencia global y no a describir ni conceptualizar propiamente los procesos de globalización o mundialización, ni menos a estudiar la dinámica de estos.

\section{La permanente creación de nuevos conceptos}

En Latinoamérica, los estudios eidéticos desde sus inicios se han encontrado con el trasplante y reelaboración de conceptualizaciones desde el quehacer europeo, donde la disciplina se venía desarrollando con anterioridad. Un primer caso fue la denominación de las tendencias eidéticas aparecidas entre nosotros y la búsqueda de conceptos que expresaran sus aspectos específicos, sin limitarse a señalar cuestiones genéricas, cuando había filiación con tendencias europeas. Ello fue ocurriendo al nombrar escuelas de

\footnotetext{
${ }^{8}$ Gérard Namer, "La memoria, el tiempo y la historia en Karl Mannheim y en Maurice Halbwachs", Stvdia Histórica. Historia Antigua, núm. 25 (2007): 23-36; Devés y Kozel, Estudios Eidéticos.

9 Juan de Dios Luque, Aspectos universales y particulares del léxico de las lenguas del mundo (Granada: Método, 2001).

${ }^{10}$ Saskia Sassen, A Sociology of Globalization (Nueva York: W.W. Norton, 2007). 
pensamiento, ${ }^{11}$ generaciones intelectuales y literarias ${ }^{12}$ y teorías interpretativas y metodologías. ${ }^{13}$

El proceso de adecuación o renovación terminológica ha ocurrido de dos maneras: agregando el apellido "americano" o "latinoamericano" para diferenciar de la formulación europea (y así se ha dicho "ilustración americana" o "romanticismo latinoamericano") o elaborar conceptos neológicos que apuntan específicamente a la novedad ("arielismo" en vez de espiritualismo latinoamericano, “cepalismo" en lugar de keynesianismo latinoamericano, "dependentismo" en vez de neomarxismo latinoamericano y así). Todavía en otros casos se han creado nociones claramente diferentes, porque en Europa no existía tal fenómeno eidético, como "indianismo" o pensamiento "decolonial".

Por otra parte, esta exploración conceptual se encuentra (y se potencia) con la búsqueda de desarrollos disciplinares, como ocurre entre especialistas que vienen realizando aportes y discutiendo los alcances de su quehacer en diversos lugares y momentos históricos, sintetizados por Horacio Cerutti en los siguientes conceptos: “influencia”, "etapas”, “retardos”, “imitación” y “originalidad”, entre otros. ${ }^{14}$

Este proceso de recepción-reelaboración, que ha sido uno de los tópicos más recurrentes en los estudios eidéticos latinoamericanos, no ha cesado de generar conceptos, hasta la actualidad, como los que se han venido mencionando y otros que continúan apareciendo en medio de la vitalidad que se advierte en este quehacer a comienzos del siglo XXI, ${ }^{15}$ llegando a hacerse un hábito de renovación conceptual, que se extiende con la aparición o consolidación de nuevos géneros eidéticos para los cuales las denominaciones anteriores parecen insuficientes. De este modo, lo que en este trabajo se denomina “ideoglobía” pretende expresar aspectos y un carácter diferente de nociones tradicionales con las cuales podría intentar conceptualizarse el caso estudiado, como son cosmovisiones,

\footnotetext{
${ }^{11}$ Leopoldo Zea, Historia del Pensamiento Latinoamericano (México: UNAM, 1979).

${ }^{12}$ Lía Berisso y Horacio Bernardo, Introducción al pensamiento uruguayo (Montevideo: Ed. Cruz del Sur, 2011), 14; Francisco Miró-Quesada, Despertar y proyecto del filosofar latinoamericano (México: Fondo de Cultura Económica, 1974).

${ }^{13}$ Horacio Cerutti, Hacia una metodología de la historia de las ideas (filosóficas) en América Latina (Jalisco: Universidad de Guadalajara, 1986).

${ }^{14}$ Ibid., 141.

${ }^{15}$ Véase Eduardo Devés, "Los estudios de las ideas y las intelectualidades en América Latina a inicios del XXI: cartografía, trazos característicos y evaluación. Un ensayo con perspectiva personal. Primera parte: Cartografía de los estudios eidéticos", Revista Wirapuru, núm. 1 (enero-junio 2020): 100-11. http://doi.org/10.5281/zenodo.4289280.
} 
teologías de amplia difusión mundial, "pan-ismos”, ideologías, "ideologías globales”, entre otras. Toda la discusión que viene supone la distinción entre lo eidético, entendido como lo relativo a las ideas, lo ideológico, en sentido estricto, como relativo a las ideologías como socialismo, liberalismo, fascismo, comunismo, entre otras.

\section{Ideología, ideología global, ideoglobía}

Para entender mejor la noción "ideoglobía" debe distinguirse de varias nociones que tenderían a confundirse.

En primer lugar, ideoglobía se distingue de expresiones eidéticas ampliamente difundidas a nivel global. Por ejemplo, la filosofía positivista posee amplia difusión global y ciertamente no es una ideoglobía. Las globías se conciben específicamente para una mejor convivencia global, después de los grandes conflictos bélicos, en el marco de un posible conflicto nuclear y donde proliferan aquí y allá conflictos localizados, que muchas personas asumen como peligroso para la seguridad mundial. Se conciben en una época donde numerosas personas, y sobre todo líderes de opinión, intentan pensar los problemas de sus sociedades en dimensión mundial, ello deriva de un apetito metanacional, es decir de un deseo por pensar y actuar más allá del Estado-nación, en este sentido no circunscriben sus propuestas al nivel de las polis respectivas, sino miran de forma supra "política", es decir, "planética". 16

En segundo lugar, se distingue de las grandes cosmovisiones y teologías milenarias (confucianismo, islam, cristianismo, entre otras). Aquello que mejor las distingue es que las ideoglobías han sido imaginadas, de modo específico, para el mundo contemporáneo de alta circulación, con diagnósticos y programas específicos, sin pretensión de validez para toda época histórica, y sin la necesidad de ocuparse de asuntos relativos al origen del cosmos ni de los seres humanos, ni recurrir a factores sobrenaturales.

\footnotetext{
${ }^{16}$ Entiendo "planética" como una forma de observar la realidad global, que inspirándose en la politología apunta a ir más allá de ella para pensar la realidad global, donde sólo existe la polis en sentido figurado, donde existen niveles de "anarquía" mayores al Estado-nación, donde no existe monopolio legal de la fuerza, a pesar de los tratados, donde no existen elecciones sino por parte de los estados en unas pocas instancias interestatales y donde se va gestando rápida y globalmente una opinión publica cuya voz es el voto sobre los asuntos que (se supone) atañen a la totalidad. Espacio mundial es a Estado-nacional, como gentecracia es a democracia, planética a politología e ideoglobía a ideología (ver Eduardo Devés, "Direitos humanos, sociedade civil e gentecracia na esfera mundial: pensando a partir do sul". En Daniel R. Cenci y Gilmar Bedin (org.) Direitos humanos, relaçoes internacionais e medio ambiente (Curitiba: Multimedia, 2013).
} 
En tercer lugar, las ideoglobías se distinguen de los "pan-ismos" (pan-arabismo, pan-africanismo, pan-asiatismo, pan-budismo, pan-eslavismo y latinoamericanismo, entre otros), que tienden a dar cuenta de la organización y agencia de grupos humanos que asumen una conciencia de colectividad afirmada en cuestiones históricas, étnicas y culturales, que no se identifican estrictamente con las delimitaciones de los estados westfalianos e incluso los continentes, representando intenciones de articulación y participación más o menos coordinada a nivel global para mejorar la obtención de sus aspiraciones étnico culturales, frente a otros grupos de individuos que supuestamente amenazan su existencia como pueblo-cultura. ${ }^{17}$ Las globías, en cambio, se pretenden más allá de toda delimitación cultural, étnica o histórica, como proyectos para la totalidad de la especie e incluso del planeta.

En cuarto lugar, se distingue también de las "ideologías", ${ }^{18}$ en tanto expresiones eidéticas que proponen opciones para la organización de las polis, especialmente para los estados-nación (ejemplo, liberalismo y socialismo entre otras). En sentido estricto, las ideologías aparecen solo en el marco del estado westfaliano, como propuestas para orientar los destinos de las polis que unifican un conjunto de factores existentes en tal modelo de Estado. Estos factores son: reconocimiento de soberanía sobre de territorios, población con derechos ciudadanos, organización de poderes independientes, monopolio de la violencia, noción de reemplazo de las autoridades, pluralidad entre formas posibles de proyectar la polis, aceptación de la existencia de circulación de la información y una arena política en la cual se disputa con un conjunto de agrupaciones que se fueron transformando en partidos, tanto para sostener como para reelaborar e implementar su ideología. De este modo, las ideologías han apuntado a gestionar el aparato del Estado y son inconcebibles sin este. ${ }^{19}$ Es significativo, además, que las polis se realizan en la medida que existen otras polis con las cuales interactúan (de modo explícito o voluntario y de modo implícito o involuntario). Por otra parte, las ideologías, deben distinguirse también de las filosofías políticas en las cuales se inspiran, tanto como de los programas políticos que elaboran los

\footnotetext{
${ }^{17}$ Eduardo Devés, Pensamiento Periférico Asia - África - América Latina - Eurasia y algo más. Una tesis interpretativa global (Santiago de Chile: Ariadna, 2017). Agradezco a Christian Álvarez algunas de ideas a este respecto.

${ }^{18}$ Freeden, Ideology.

${ }^{19}$ Ibidem.
} 
partidos como formulaciones específicas, normalmente imaginadas para coyunturas electorales. $^{20}$

Otro aspecto que induce a cierta confusión entre ideoglobía e ideología es que, en numerosas oportunidades, los partidos de polis diversas, inspirados en las mismas o cercanas formulaciones ideológicas, se han asociado en alianzas estratégicas. Estas coordinaciones se han llamado normalmente "internacionales", derivadas de la propuesta socialista y marxista, aunque ampliándose también hacia el social-cristianismo, liberalismo, ecologismo y otros. Este fenómeno es el que produce mayor similitud (y confusión) entre ideologías e ideoglobías, pues tales ideologías pretenden comportarse como ideoglobías.

De hecho, en esta pretensión existe un importante antecedente para las ideoglobías, ello fue particularmente elaborado por el socialismo durante la segunda mitad del siglo XIX, que se concibió como un proyecto que se realizaría a nivel mundial, que requería una revolución mundial, apuntando incluso a la propuesta de una unidad política mundial, en un solo aparato administrativo. Marx, asumió que el socialismo como sistema sólo podría realizarse de manera global, generando una argumentación en la cual el comunismo debería pensarse más como ideoglobía que como ideología (en lo que se transformó de hecho unas pocas décadas después de su muerte) Esto, en la medida, que muchos socialistas se fueron dando cuenta que la revolución europea no vendría tan rápido, que la conciencia nacional era más fuerte que la conciencia socialista y que quienes poseían sólo prole y cadenas difícilmente podían gestionar así simplemente una conciencia global, pues para eso debía poseerse tremenda cantidad de información y conocerse de cerca, incluso experiencialmente, múltiples expresiones de la circulación mundial.

En quinto lugar, debe distinguirse de "ideología global”. La noción "ideología global" tiene dos sentidos uno "ingenuo" como una ideología que se encuentra en muchos lugares del mundo (por ejemplo, al decir "en los años ochenta, el socialismo fue una

\footnotetext{
${ }^{20}$ En tal sentido, la noción de polis global y de ideología global se estiran demasiado, generando una distorsión en todo el conocimiento al respecto, por ello es más adecuado imaginar el mundo de modo planético y no político, donde tampoco puede haber interacción con otras polis, pues sería la polis única, y donde todos los apetitos desearían transformarse en dictaduras globales y algunos lo lograrían, imponiendo una dictadura de clase-raza global. En este caso es necesario nuevamente insistir en la distinción entre lo ideológico en sentido estricto, como aquello referido solo al conjunto de las ideologías políticas y lo eidético, como aquello relativo a las ideas, en general.
} 
ideología global, pues se consideraba una opción en lugares de los cinco continentes, como ocurriría con el neoliberalismo en los años dos mil") y uno "específico", como una ideología que no opera a nivel nacional sino en opera en dimensión global, en virtud de su carácter como expresión eidética, específicamente elaborada para operar de tal modo. Tales traslapes han llevado a concebir el "globalismo" como una ideología. ${ }^{21}$

Las argumentaciones anteriores, que apuntan a señalar la diferencias, no logran olvidar la existencia de traslapes entre las expresiones eidéticas y sobre todo en las maneras como la comunidad académica las percibe, denomina y reelabora, teniendo además en cuenta que las ideoglobías heredan y se nutren de sistemas filosóficos, ideologías e incluso de teologías milenarias, como obviamente de la producción académica reciente. De hecho, existen formas de traslape, sobre todo con las ideologías, tanto porque algunos de los grandes estados tienden a pensarse como gestores del mundo, cuanto porque el mundo adquiere ciertas formas de megapolis, con numerosos organismos de gestión, siguiendo en algunos aspectos el modelo de un Estado-nación. Además de ello, históricamente, la propia construcción de los Estados-nación supuso la composición de varios localismos en un todo mayor y para algunas figuras intelectuales este camino hacia una mayor universalización continúa en vistas a algo así como un "Estado mundial".22

La diferencia consiste principalmente en el carácter de la entidad eidética (cuyos casos se ofrecen en la parte $B$, más adelante)

En la medida que la ideoglobía se asume como una forma de mejorar la convivencia global, que se manifiesta en un imaginario global de la mano de la economía, las políticas internacionales, las cuestiones comunicacionales y, sobre todo, los fenómenos ambientales, que han sido claves para hacernos sentir cotidianamente, por los medios de comunicación, como embarcados en un destino común. Ello ha conducido a la convicción que si los problemas son comunes también deben serlo las formas de solucionarlos. Así se realizan mucho mejor en el seno de la ONU y otros organismos internacionales, como en el

\footnotetext{
${ }^{21}$ Steger, "Political Ideologies".

${ }^{22}$ Alexander Wendt, "Why a World State is Inevitable", European Journal of International Relations, 9, núm. 4 (diciembre, 2003): 491-592. https://doi.org/10.1177/135406610394001. Por otra parte, las nociones que diferencian estas dimensiones contribuyen a segmentar los espacios de poder, resguardando espacios de libertad, de ahí que sea deseable la mantención de lo domestico, lo político y lo planetario, como formas de resguardos y equilibrios. Aunque este problema no constituye objeto de este trabajo.
} 
desarrollo de una opinión pública global que no funciona en el marco westfaliano, aunque sí suponiendo al conjunto de los Estados-nación como partes decisivas de una dinámica global. En este sentido, las ideoglobías se imaginan más bien como pactos globales que como disputas por el poder global, asumiendo más bien que no son modelos de construcción de la polis, sino marcos que permitan la convivencia de polis y la supervivencia de todos $\mathrm{y}$, precisamente, donde no existe la realidad ni la noción ampliamente aceptada de un Leviatán que pueda ni deba mantener el orden mundial, aunque algunas potencias imperiales, y Estados Unidos, superlativamente, hayan querido convertirse en gran Leviatán, que ordene los asuntos globales. La URSS, la UE, China, Rusia y todo el mundo han imposibilitado que se materialice este designio usamericano. Sea como fuere, desde los años sesenta vienen apareciendo formulaciones eidéticas que se han venido constituyendo propiamente como ideoglobías. Esto es lo que se presenta en el acápite siguiente.

\section{Segundo camino: algunas de las ideoglobías operantes}

Algunas de las ideoglobías presentes en la opinión pública actual son: El "noeismo" de NOEI, sigla de la propuesta del Nuevo Orden Económico Internacional, el "gobernancismo global", el "neo-tianchaismo", el "ambientalismo" y el "derecho-humanismo". Estas no son las únicas, puede incluso considerarse como ideoglobía algunas versiones del ambientalismo.

Las ideoglobías propiamente tales, sólo pueden formularse en situaciones mundiales de alta circulación (transporte, mensajes, personas, capitales, enfermedades) y gentecracia (mucha gente opinando sobre problemas que se conciben más allá del Estadonación). Adquieren mayor relevancia en la medida que las más variadas gentes del mundo se interrelacionan y lo hacen con mayor frecuencia y fluidez cuestión cuyo incremento es fácil de advertir a lo largo de las últimas décadas. Por ello puede sostenerse que son "nuevas" o "renovadas", aunque han existido formas de proto-globías, en otros momentos de la historia del pensamiento. De hecho, grandes conglomerados anteriores albergaron concepciones sobre modelos de existencia "internacional" armónica, para circunstancias 
de relativamente baja circulación y casi nula gentecracia. ${ }^{23}$ Son los casos, por ejemplo, de la propuesta "Tianxia" elaborada en China por la dinastía Zhou hace unos tres mil años y de la "Pax Romana" de hace unos dos mil años. Sobre la primera, se ha dicho que se originó en una situación donde se hacía impracticable el dominio por la fuerza y donde se imaginó algo como una red o un sistema, que desarrollaría interdependencia entre todas las naciones considerando beneficios relacionados y bienes compartidos. ${ }^{24}$ Sobre la segunda, se ha planteado que Virgilio, a través de la Eneida, le otorgó a esta proto-ideoglobía un sentido mítico tanto como empírico; Eneas, unía Asia, África y Europa en la fundación de Roma y bajo el gobierno del emperador Augusto. ${ }^{25}$

En estos casos, se denominan como "proto ideoglobías", por tres razones. En primer lugar, porque son formuladas por la intelliguentsia de los imperios, en escenarios con muy pocos agentes de pensamiento y de escasa pluralidad eidética, en épocas con bajísima opinión pública mundial $\mathrm{y}$, por tanto, sin gentecracia, es decir carentes de la inmensa cantidad de agentes pensantes, con cientos y miles de ecosistemas intelectuales en funcionamiento e intercambio, como ocurre hacia el 2000. En segundo lugar, son formuladas con información muy escasa sobre las diversas regiones del mundo y con menores posibilidades de actualización de esa información. En tercero, son formuladas en escenarios de baja circulación, a diferencia de la actualidad con un sistema de transporte de personas y de comunicación frecuente y fluida. De hecho, la circulación de alta frecuencia es casi impensable hasta la segunda mitad del siglo XIX, con un sistema de comunicación relativamente global, que comprende simultáneamente el telégrafo, el barco a motor, el ferrocarril y la prensa. Ello debe ser acompañado por un factor imprescindible: una cantidad amplia de ecosistemas intelectuales capaces de emitir ideas hacia el mundo y suficientemente representativos de diversos sectores de la humanidad. Ello parcialmente se logra hacia mediados del siglo XX, con las independencias de Asia y África, y se realiza

\footnotetext{
${ }^{23}$ François-Bernard Huyghe, "Cuando las ideas andaban a pie”, El Correo de la Unesco, 50 (junio, 1997): 69.

${ }^{24}$ Zhao Tingyang, The China Dream in question (Cambridge MA: Harvard-Yenching Institute Working Paper Series, 2013), 2.

${ }^{25}$ Véase, entre otros Pedro López Barja de Quiroga, Imperio legítimo: El pensamiento político en tiempos de Cicerón (Madrid: Antonio Machado Libros, 2007) y Rubén Olmo, "La idea imperial en Virgilio", en Espacio, Tiempo y Forma. Serie II, Historia Antigua, núm. 21 (enero, 2008): 259-273.
} 
casi cabalmente sólo a fines de dicho siglo, cuando se alcanza suficiente cantidad de emisiones de pensamiento femenino.

Las globías actuales, y no podía ser de otra manera, toman elementos de formulaciones anteriores y los reelaboran, ahora de modo más consciente, en la medida que existen vastas comunidades intelectuales y burocracias que se encuentran incentivadas a generar sistemáticamente ideas nuevas.

El noeismo (de Nuevo Orden Económico Internacional) asume la existencia de grandes desigualdades en el espacio internacional, derivadas de diferencias de poder político y económico, ${ }^{26}$ existencia de relaciones muy desiguales y dependencia, a nivel mundial. Esta propuesta se ha asociado a nociones como "centro/periferia", "deterioro en los términos del intercambio", "relaciones Norte/Sur", principalmente y a tendencias como el tercermundismo ${ }^{27}$, el cepalismo, ${ }^{28}$ luego al dependentismo ${ }^{29}$ y a las primeras propuestas del Club de Roma. ${ }^{30}$ Se trató de un debate importante en los setenta y ochenta, como lo muestra la misma bibliografía, perdiendo luego vigencia, aunque no desapareciendo completamente.

"Nuevo Orden Económico Internacional" fue una expresión acuñada en la VI asamblea especial de las Naciones Unidas en $1974,{ }^{31}$ que hacía referencia de modo genérico a las peticiones que presentaban los países subdesarrollados. Estas peticiones

${ }^{26}$ Celso Lafer, "Reflexiones sobre el tema del nuevo orden mundial en un orden internacional en transformación", Estudios Internacionales, 15, núm. 58 (abril-junio, 1982): 127-165. https://doi.org/10.5354/0719-3769.2011.16047.

27 Germán Alburquerque, "Tercermundismo en el Cono Sur de América Latina: ideología y sensibilidad. Argentina, Brasil, Chile y Uruguay, 1956-1990”. Tempo e Argumento, 6, núm. 13 (septiembre-diciembre, 2014): 140-173. http://dx.doi.org/10.5965/2175180306132014140.

${ }^{28}$ Raúl Prebisch, "Cinco. etapas de mi pensamiento sobre el desarrollo", Comercio Exterior, 37, núm. 5 (mayo 1987): 345-352; Robert Cox, "Ideologies and the New International Economic Order: Reflections on some recent literature", International Organization, 33 núm. 2 (marzo-julio 1979), 257-302. https://doi.org/10.1017/S0020818300032161; Enrique Oteíza, A. Rahman, R.Green y C. Vaitsos, "Technical Co-operation among Developing Countries as a New Dimension of International Cooperation for Development. An Outline" United Nations. A/CONF. 79/PC/12, (1 de Julio 1977). Preparatory Committee for the UN Conference on Technical Cooperation among Developing Countries.

${ }^{29}$ Eduardo Devés y César Ross, Las ciencias económico-sociales latinoamericanas en África Sudsahariana (Santiago de Chile: Ariadna, 2009); Samir Amin, "Self-reliance and the New International Economic Order", Monthly Review, vol 29 núm. 3 (julio- agosto 1977): 1-21. https://doi.org/10.14452/MR-029-03-1977-07_1; Cox, "Ideologies".

${ }^{30}$ Jagdish N. Bhagwati (ed.), The New International Economic Order: The North-South Debate (Cambridge MA: The Massachusetts Institute of Technology Press, 1977).

${ }^{31}$ Cox, "Ideologies", 257. Señala que esta noción se habría lanzado en 1973 en la reunión de los No Alineados en Argel. 
apuntaban a las formas de funcionamientos de la economía internacional. El término NOEI vino a sustituir al de "ayuda al desarrollo" e implicaba la existencia de una determinada estructura: el desorden económico que perpetuaba la posición de pobreza de los países subdesarrollados. En este esquema, el mundo "está regido por un sistema que se estableció en una época en que la mayoría de los países en desarrollo ni siquiera existían como Estados independientes y que perpetúa la desigualdad". Muy importante en esta propuesta fue la UNCTAD, (del inglés, United Nations Conference on Trade and Development) creada en 1964 para asuntos relacionados con el comercio, las inversiones y el desarrollo. ${ }^{32}$ Los objetivos principales de la organización han sido "promover el comercio internacional y el desarrollo económico de los países en desarrollo", "promover la cooperación entre países en distintas etapas de desarrollo" y "promover un orden económico internacional más equitativo". 33

El gobernancismo-global, si puede llamarse así, tiene su "manifiesto fundacional" en el documento evaluado por la comisión presidida por el alemán Willy Brandt en 1995: "Our Global Neighborhood. Report of the Commission on Global Governance". Este comenzó a gestarse, según lo resume Zirahuen Villamar, a finales de 1989, semanas después de la caída del Muro de Berlín, cuando Brandt invitó a integrantes de anteriores comisiones internacionales de las Naciones Unidas sobre temas específicos a una reunión en la cual se plantearían nuevos desafíos. Allí participaron personas de la propia Comisión Brandt sobre asuntos de desarrollo internacional, de la Comisión sobre Desarme y Seguridad, de la Comisión sobre Medio Ambiente y Desarrollo y gente de la Comisión Sur. ${ }^{34}$ Meses más tarde, el sueco Ingvar Carlsson y el guyanés Shridat Ramphal fueron designados para presidir una nueva comisión de la ONU. De acuerdo a la propuesta de Willy Brandt, esta nueva comisión discutiría la "gobernanza global". En 1992 BoutrosGhali, como secretario general de la ONU, respaldó la iniciativa de dicha comisión y 26 personas de nacionalidades y profesiones diversas fueron convocadas a participar. En 1994,

\footnotetext{
${ }^{32}$ Gamani Corea, Need for Change: Towards the New International Economic Order (Oxford: Pergamon Press, 1980).

${ }^{33}$ UNCTAD, The History of UNCTAD. 1964-1984 (Nueva York: United Nations, 1985), 12-13.

${ }^{34}$ Zirahuén Villamar, "Gobernanza Global y (su propio) desarrollo", Revista de Relaciones Internacionales de la UNAM, núm. 127 (enero-abril, 2017): 135-149.
} 
la Comisión finalizó sus trabajos con la publicación del reporte Nuestro barrio global con una definición de "gobernanza global". ${ }^{35}$

El documento ${ }^{36}$ se inicia con varios axiomas: "El poder colectivo de la gente para configurar el futuro es mayor que nunca antes y la necesidad de ejercerlo es más acuciante. Movilizar este poder para hacer la vida en el siglo XXI más democrática, más segura y más sustentable es el principal desafío de esta generación. El mundo necesita una nueva visión". Inmediatamente se ocupa del concepto "gobernanza global" que es definido como "la suma de muchas formas en que individuos e instituciones, públicos y privados, manejan los asuntos comunes". Más aún se trata de "un proceso continuo, por el cual intereses diversos o en conflicto deben ser acomodados para llevar a cabo acciones cooperativas" y ello solo es comprensible en relación con "enorme crecimiento del compromiso de la gente con los derechos humanos, la equidad, la democracia, uniendo necesidades materiales básicas, protección ambiental y desmilitarización" que ha producido en la actualidad "una multitud de nuevos actores que pueden contribuir a la gobernanza". Todo ello conduce a reconocer, señala el documento, que "los gobiernos no deben cargar con todo el peso de la gobernanza global", aunque ello "no implica, sin embargo, gobierno global o federalismo global". Thomas Legler lo ha resumido así: "La gobernanza global como método de resolución de problemas se relaciona con la idea de llenar los vacíos de gobernanza" allí donde "no hay soluciones globales ni regulaciones adecuadas". Esta noción, según Legler, "se afirma en el siguiente axioma: La globalización contrae al planeta de tal manera que todas las sociedades, comparten un destino común ante una serie de problemas globales que producirán graves consecuencias para toda la humanidad, si no se abordan de manera oportuna y decisiva a través de una mayor cooperación". ${ }^{37}$

El neo-tianxiaismo se está reelaborando a inicios del siglo XXI, en el marco de la mayor presencia de China a nivel mundial. Según Qin Yaqing uno de los pensadores chinos que trabaja sobre esta propuesta: "es muy pertinente hoy en día donde los esfuerzos basados

\footnotetext{
${ }^{35}$ Ibid., 138.

${ }^{36}$ Commission on Global Governance, Our Global Neighborhood. The Report of the Commission on Global Governance (Oxford: Oxford University Press, 1995).

${ }^{37}$ Thomas Legler, "Gobernanza Global", en Thomas Legler, Arturo Santa Cruz, y Laura Zamudio González (eds.), Introducción a las Relaciones Internacionales: América Latina y la Política Global (México: Oxford University Press, 2013), 255.
} 
en la fórmula de los estados-nación están abocados al fracaso". ${ }^{38} \mathrm{Si}$, de hecho, la globalización se ha transformado en un fenómeno mundial, en el plano institucional y filosófico, todavía no existe un "mundo”, más allá de la mera denominación geográfica.

El neo-tianxiaismo diagnostica que las relaciones internacionales están marcadas por paradigmas occidentales, donde los criterios son la competencia y el poder: Maquiavelo, Hobbes, Marx, Freud, Schmitt, Morgenthau. Según Zhao Tingyang, el mayor logro es "una mente en paz, libre de las trampas de pensar en términos de guerra, enemigo, vencedor y perdedor". ${ }^{39}$ Por su parte, en el plano conceptual, el sistema Tianxia se afirma en tres ideas: en primer lugar, las soluciones a los problemas de la política mundial dependen de un sistema mundial universalmente aceptado y no de la fuerza coercitiva; en segundo lugar, dicho sistema está justificado en términos políticos si sus acuerdos institucionales benefician a todos los pueblos; $y$, en tercer lugar, dicho sistema funciona si genera armonía entre todas las naciones. ${ }^{40}$

En pocas palabras, sería un sistema del mundo, en sentido genuino, no de los Estados, que daría lugar a un sistema legítimo y responsable para el conjunto del mundo y no solo para los Estados-nación. ${ }^{41}$ De este modo, el sistema Tianxia refleja un "mundismo" auténtico y ello se confronta con el hecho que las instituciones existentes han sido creadas por y para los estados, sobre la base de sus intereses y, por lo tanto, son incapaces de superar los límites del Estado-nación.

Esta visión se afirma históricamente, según la tesis de Zhao Tingyang, ${ }^{42}$ otro de los expositores de este pensamiento, en la sociedad china tradicional, donde los principios utilizados en el seno de una familia se extienden a todos los colectivos sociales, incluyendo

\footnotetext{
${ }^{38}$ Qin Yaqing, "Cultura y pensamiento global: una teoría china de las relaciones internacionales", Revista CIDOB d'Afers Internacionals, núm. 100 (diciembre 2012): 67-90.

${ }^{39}$ Qin, "Cultura", 75-76.

40 Zhao, China Dream.

${ }^{41}$ Qin, "Cultura".

42 Zhao Tingyang, A World without a Worldview: Political Philosophy and Cultural Philosophy (Guilin: Guangxi Normal University Press, 2005); Zhao Tingyang, "Rethinking Empire from a Chinese Concept 'Allunder-heaven", $\quad$ Social Identities, 12, núm. $1 \quad$ (enero, 2006): 29-41. https://doi.org/10.1080/13504630600555559.
} 
el Estado y el mundo en su conjunto o, según el pensamiento chino tradicional, los mismos principios $^{43}$ y valores se pueden aplicar a escala universal. ${ }^{44}$

El ambientalismo ha dado lugar a diversas expresiones eidéticas en una familia que tanto se acrecienta como se ramifica. De hecho, en las primeras décadas del siglo XXI, encontramos inspiraciones ambientalistas en cotidianías, ${ }^{45}$ en ideologías que inspiran a partidos políticos, en tratados filosóficos y formulaciones ideoglóbicas, que son las que interesan aquí.

Respecto de este último caso, es particularmente importante la cantidad de conferencias internacionales que, siendo consideradas por muchos especialistas como meramente formales y de pocos y nulos resultados efectivos, han otorgado al ambientalismo una visibilidad mundial que ha facilitado su formulación o su comprensión como ideoglobía o, al menos, como componente imprescindible de cualquier ideoglobía en estos tiempos, ${ }^{46}$ siendo en esto un hito la conferencia de Estocolmo en 1972. Se ha dicho que desde entonces se ha desarrollado una cooperación a nivel global a través de tres formulas principales: "la consolidación de organizaciones científicas que proveen un conocimiento detallado sobre los problemas del medio ambiente; la creación de instancias de diálogo y coordinación política; y la creación de mecanismos normativos universales legalmente vinculantes". ${ }^{47}$ Todo ello en relación también a programas de investigación en relación con estos asuntos:

\footnotetext{
${ }^{43}$ Qin, "Cultura", 75-76.

$44 \mathrm{Tu}$ Wei-Ming, "Asian Values and the Asian Crisis: A Confucian Humanist Perspective" en www.ruf.rice.edu/ tnchina/comentary/tu1098.html.

${ }^{45}$ Las cotidianías son expresiones eidéticas que aspiran a fundamentar un quehacer por el cual se adquiere una vida buena o mejor, en dimensiones físicas y psíquicas, por parte de quienes lo practiquen, de modo inmediato. No pretenden dar sentido a la totalidad de la existencia personal, ni menos de toda la sociedad, y por ello no se proponen cambiar las estructuras, ni menos convencer a la humanidad de sus beneficios. Ejemplos de estas son el "yoguismo" (no confundir con la filosofía yoga), el "futbolismo (no confundir con la práctica del futbol ni con los reglamentos de la FIFA), y el "jardinerismo" (no confundir con la agronomía, con el paisajismo ni con el diseño de jardines, aunque puedan traslaparse), entre otras (ver Devés, Eduardo, "Cotidianías" en América Latina actual: conceptos, géneros, contrastes, Estudios Avanzados, núm. 34 (2021): 1-14. https://doi.org/10.35588/estudav.v0i34.4824.

${ }^{46}$ En relación a esto podría hablarse no solo de ideoglobías como expresiones eidéticas completas, sino de "componentes ideoglóbicos" o "dispositivos ideoglóbicos" que, si bien por sí mismos no son suficientes para constituir una ideoglobía, parecen necesarios para cualquiera imaginable, en esta época.

${ }^{47}$ Matías Franchini, Eduardo Viola y Ana Barros-Platiau, "Los desafíos del antropoceno: de la política ambiental internacional hacia la gobernanza global", Ambiente \& Sociedade São Paulo, 20, núm. 3 (julioseptiembre, 2017): 179-206, doi: https://doi.org/10.1590/1809-4422asoc214v2022017.
} 
economía ambiental, economía ecológica, sociología de los movimientos sociales, derecho de tercera generación [...], etc. Los estudios políticos, en ese campo de fronteras borrosas formado por la teoría política, la ciencia política, la sociología política y la filosofía política, no se han quedado a la zaga [...]. Esto ha tenido lugar ya apropiándose de términos clásicos (como) contrato natural, ecocentrismo, ética de la tierra, derechos ambientales [...] ya gracias a la aparición de un nuevo léxico (como) entropía, sostenibilidad, desarrollo sostenible, producción limpia, etc. ${ }^{48}$

En consecuencia, van apareciendo numerosas nociones como "partido verde", "economía verde", un "pensamiento político verde", que van instalando ideas que se van articulando, cubriendo variados ámbitos. Ello se extiende a la ética, la teoría social, la filosofía, la teoría política y al derecho, entre otras disciplinas. De este modo, argumenta Valdivielso, "Estaríamos ante un proyecto ilustrado (selectivo) emancipador, que reconoce límites naturales, y que pone en cuestión todo un 'paradigma dominante' desde la Ilustración”. ${ }^{49}$ Este racimo eidético cuestionaría numerosos elementos de la propuesta ilustrada, pero "es selectivo, ya que, aunque aspira a superar creencias compartidas por proyectos liberales y marxistas, humanistas y autoritarios, se reserva la reivindicación de otros aspectos de la modernidad, como la defensa de los derechos humanos, la justicia y la igualdad". ${ }^{50}$

Los aportes se suman desde diversas regiones del mundo, por ejemplo, desde América Latina muy temprano "en 1977 se dio a conocer el denominado Informe Bariloche bajo el título ‘¿Catástrofe o nueva sociedad? Modelo Mundial Latinoamericano’, en donde se destacaron diferencias sustanciales entre los países desarrollados y en desarrollo". ${ }^{51} \mathrm{El}$ cambio climático, en su alteración de los aspectos básicos de la supervivencia biológica,

\footnotetext{
${ }^{48}$ Joaquín Valdivielso, "La globalización del ecologismo. Del ecocentrismo a la justicia ambiental", Medio Ambiente y Comportamiento Humano, 6, núm. 2 (2005): 183-204.

${ }^{49}$ Ibid., 191.

${ }^{50}$ Ibidem.

${ }^{51}$ Marina Laura Lanfranco, “Ambientalismo", en Hugo Biagini y Arturo Roig (dir.), Diccionario del Pensamiento Alternativo Tomo II (Buenos Aires: Biblos, 2008); Amílcar Herrera, ¿Catástrofe o Nueva Sociedad? Modelo mundial latinoamericano (Bogotá: CIID, 1978); Fernando Estenssoro y Eduardo Devés, "Antecedentes históricos del debate ambiental global: Los primeros aportes latinoamericanos al origen del concepto de Medio Ambiente y Desarrollo (1970-1980)", Estudos IberoAmericanos, 39, núm. 2 (juliodiciembre, 2013): 237-261; Fernando Estenssoro, Historia del debate ambiental en la política mundial 19451992. La Perspectiva Latinoamericana (Santiago de Chile: Instituto de Estudios Avanzados, Universidad de Santiago de Chile, 2014).
} 
contribuye a que el ambientalismo participe con mayor importancia y/o frecuencia en una ideoglobía, o como aspecto inherente a varias de estas ${ }^{52}$.

El derecho-humanismo es una entidad eidética que tiene la noción derechos humanos como núcleo, articulando en torno a esta, elementos de diversas tendencias, provenientes del clúster "estado de bienestar" y liberalismo político, con algunos aspectos del ecologismo, de las teorías feministas y del derecho internacional. Este ensamblaje eidético pretende ser capaz de regular, mejor que otras ideoglobías, la convivencia global.

Me tomo de Samuel Moyn, y de su libro La utopía de los Derechos Humanos, para señalar que la noción "derechos humanos" se ha posicionado como un valor cultural, moral y político con alcance global en las últimas décadas. Ello no ocurrió en 1948 cuando se aprobó la Declaración Universal, sino desde los setentas. Fue en esta década, que los derechos humanos empezarían a ser invocados por cantidades notoriamente mayores de personas que en el pasado, en circunstancias variadas. Ello supuso el abandono de otras causas que movilizaban a diversos sectores (los movimientos pacifistas, los movimientos sociales surgidos a propósito del mayo 1968 francés, los movimientos cristianos, el comunismo, el Nuevo Orden Económico Mundial, las luchas anticoloniales por la autodeterminación de los pueblos, etc.), al decir de Felipe Galvis. ${ }^{53}$ En otras palabras, en lugar de referirse a la liberación colonial y a la creación de naciones independientes, los derechos humanos ahora significaban más frecuentemente la protección individual frente al Estado. ${ }^{54}$ Ello se hizo muy patente cuando Amnistía Internacional obtuvo el Premio Nobel de la Paz en 1977. A partir de ese momento, piensa Moyn, "la popularidad de este nuevo modelo de defensa y promoción de los DDHH [...] dio origen a una nueva marca para la promoción de estos derechos, basada en la idea de un ciudadano internacional". ${ }^{55}$

La noción derechos humanos no nació como ideoglobía, sino que ha llegado a ser el núcleo de una de éstas. Ello ha sido posible tanto porque la noción ha tenido mutaciones,

\footnotetext{
52 Debo esta formulación a Christian Álvarez.

53 Felipe Galvis, "Samuel Moyn, La última utopía: los derechos humanos en la historia", Estudios SocioJurídicos, 19, núm. 1 (enero-junio, 2017): 167-176.

${ }^{54}$ Samuel Moyn, La última utopía: los derechos humanos en la historia (Bogotá: Universidad Javeriana, 2015), 13-15.

55 “Derechos humanos" apareció en 1977 en el New York Times cerca de cinco veces más a menudo de lo que había aparecido cualquier año anterior (Moyn, La última, 14).
} 
ampliaciones y reinterpretaciones a lo largo y ancho del mundo y de las décadas, como por las "funciones" que ha ido cumpliendo. ${ }^{56}$

Ante esta situación es clave preguntarse ¿cuáles fueron los pasos (u operaciones) en este proceso? Algunos de estos se refieren a cuestiones propiamente eidéticas, como cuestiones de antropología filosófica y filosofía del derecho, aunque deben tenerse en cuenta igualmente los cambios en la función cumplida por el derecho-humanismo, al interior de muchos ecosistemas intelectuales. Un asunto clave para esto consiste en entender cómo es que el derecho-humanismo pasó de ser un dispositivo (que se "adhería" a otras expresiones eidéticas) a constituirse en una ideoglobía propiamente tal. Pero cuidado, no se trata solo de un cambio en cuestiones de "contenido", si puede decirse así, sino de "función". No cambió tanto la noción "derechos humanos" sino la concepción del valor de la noción para alcanzar una legitimidad no sospechada anteriormente.

A propósito de esto señala Moyn:

La mejor explicación general sobre los orígenes de este movimiento social y el discurso común alrededor de los DDHH continúa siendo el colapso de otras utopías previas, tanto las que se basaban en el Estado nación como aquellas fundadas en alguna versión u otra del internacionalismo. Estos serían sistemas de creencias que prometían un estilo de vida libre, pero terminaron en ríos de sangre, u ofrecían... En medio de esta atmósfera, surgió un internacionalismo construido alrededor de los DD individuales, y apareció porque fue definido como una alternativa pura en una era de traiciones ideológicas y colapso político. ${ }^{57}$

El ascenso del derecho-humanismo como ideoglobía fue entonces la consecuencia de una combinación de factores que interactuaron, desatando una reacción en cadena. ¿Cómo se logró entonces la constitución del derecho-humanismo como ideoglobía, en esa reacción en cadena: sus agencias, sus astucias, sus tácticas, sus alianzas? ${ }^{58}$

\footnotetext{
${ }^{56}$ Entiendo por "función" la capacidad de satisfacer una demanda de sentido de los seres humanos. En este caso, la capacidad de transformarse para satisfacer una necesidad de la sociedad civil global. En este proceso es clave la legitimidad que le viene de haberse aprobado en la ONU la Declaración Universal de los Derechos Humanos en 1948, aunque ello no sea suficiente.

${ }_{58}^{57}$ Moyn, La última, 18.

${ }^{58}$ Nótese que me refiero al derecho-humanismo como expresión eidética desarrollándose en millones y millones de inteligencias y no a alguna decisión o conspiración de unos pocos agentes que imaginaron astucias y alianzas, por otra parte, sin descartar esta dimensión.
} 
Presentaré cinco operaciones.

Operación 1. Asociarse con otras tendencias eidéticas que ganaban protagonismo en el mismo momento. La noción de derechos humanos se asoció, racimándose, con el ambientalismo (amplio y variopinto) y con un neodemocratismo, de lo que se llamó la tercera ola democratizadora. ${ }^{59}$ Las formas de asociación entre estas tendencias se han expresado en nociones como el derecho a la vida en un medioambiente limpio y la democracia como antidiscriminación. Más aún, democracia y derechos humanos han llegado a constituirse como sinónimos en cierto plano: la comprensión de la democracia como realización de los derechos humanos y los derechos humanos como democracia. ${ }^{60}$ En esta sinonimia se encontró también con tendencias feministas y de reivindicación de orientaciones sexuales.

Operación 2. La noción base de derechos humanos fue gozando de mutaciones y ampliaciones o, por decirlo así, fue buscando y encontrando un camino. El mismo Moyn ha señalado al respecto que la "ambigüedad que condenó los derechos humanos al fracaso en el plano de la política internacional durante los cuarentas, sería al final una razón más para su extraño triunfo décadas después. Fue justamente esta ambigüedad la que les permitió regresar más tarde "con una vestimenta diferente"" ${ }^{61}$ Ejemplo de ello fueron cuestiones como el tema de los derechos de las personas lesbianas, gays, bisexuales y trans; la situación de los pueblos indígenas, especialmente en lo relativo al derecho de no discriminación; las garantías de ciertos derechos a los migrantes indocumentados, entre otras cosas. ${ }^{62}$ Ello fue paulatinamente permitiendo a la noción hacerse cargo de nuevos asuntos que no estaban en la formulación original y que eran muy relevantes en las discusiones entre fines del siglo XX e inicios del XXI.

Operación 3. Llegar a constituirse en parte de la mentalidad y la cultura de un importante porcentaje de la gente que ha pasado por la universidad. Es decir, el derechohumanismo no sólo ha realizado mutaciones propiamente eidéticas, como se ha visto en las operaciones anteriores, sino también ha ganado un status cultural. De este modo, el

\footnotetext{
59 Samuel Huntington, La tercera ola democratizadora. La democratización a finales del siglo XX (Barcelona: Paidós Ibérica, 1994).

${ }^{60}$ Galvis, "Samuel Moyn".

${ }^{61}$ Moyn, La última, 170.

${ }^{62}$ Antonio Augusto y Cançado Trindade, Tratado de Direito Internacional dos Direitos Humanos. Volume I (Porto Alegre: Sergio Antonio Fabris, 1997), 347.
} 
derecho-humanismo ha tenido la capacidad de constituirse en criterio de la cultura de gente solidaria y de buena voluntad egresada de la educación superior (de modo muy parecido al ambientalismo, por otra parte), tanto en países del centro como de sus periferias culturalmente más dependientes (Sudamérica, Europa Oriental), sin olvidar a millones de intelectuales y estudiantes de las regiones menos dependientes, culturalmente hablando, que pasan años de su vida estudiando o trabajando en el centro (China, India, África, Asia Central). El derechohumanismo se convirtió en parte de esta cultura porque había sido asumido como dispositivo por teologías e ideologías y por programas de partidos políticos influyentes, siendo, a la vez, suficientemente no conflictivo, no generando así demasiadas reacciones represivas. Es decir, una mentalidad-cultura del respeto y del pacifismo, más democrática que autoritaria, más de diálogo que de confrontación, y que permitía por igual enfrentar cuestiones sexuales, políticas, familiares, económicas, donde se podía hablar de las cárceles y los campos de concentración, de las salas de clase y de los lugares de trabajo, del transporte público, de las reuniones familiares y de la cama. Un criterio o valor hegemónico en este medio y que comenzó a funcionar como principio legitimador de prácticas y discursos. ${ }^{63}$ Un conjunto de criterios suficientemente abiertos para permitir innúmeras acentuaciones, ampliaciones y reinterpretaciones, e independientes de algún agente capaz de imponer una ortodoxia cerrada.

Operación 4. Ocupar el "vacío de sentido" dejado por otras causas. Hubo antiguas causas que perdieron sentido, parcialmente la descolonización y el socialismo, como también aparecieron nuevos desafíos que se hacían manifiestos ante las dictaduras y genocidios en Sudamérica, Asia y África, para los cuales faltaban argumentaciones convocantes. Presentado con otras palabras: el discurso del derechohumanismo se fue transformando en fuente de sentido para causas humanitarias en lugares muy diversos y como criterio global para reivindicar derechos en tantos países, muchos de los cuales habían luchado poco antes por la emancipación colonial y el socialismo, pero que luego caían en sucesivas guerras civiles e internacionales y dictaduras.

Operación 5. Expresar sus reivindicaciones a través de formas muy variadas, de prácticas mixtas y no excluyentes, según agentes y coyunturas: organismos internacionales, ONG, movimientos sociales, práctica diplomática, de comisiones e iglesias y

\footnotetext{
${ }^{63}$ Galvis, "Samuel Moyn".
} 
manifestaciones en calles y plazas. Los cambios eidético-culturales se acompañaron, se gestaron y manifestaron también, en una eclosión de nuevas prácticas relativas a nuevas causas de nuevos y antiguos agentes sociales. ${ }^{64}$ En la medida que se fue constituyendo como globía y, por ello, haciendo sentido a personas de diversas naciones y culturas, se abrieron mayores posibilidades a la pluralidad de expresiones. El derechohumanismo es además en general pacifista, inhibiendo (no eliminando) reacciones de violencia con peligro de muerte en su contra. Además, por ser altamente descentralizado puede gozar de múltiples interpretaciones y acentuaciones, sin perder cierta identidad básica.

\section{Conclusiones}

Se ha intentado avanzar en la elaboración de un concepto que defina un tipo de expresiones eidéticas, que en nuestra época se alojan y reproducen en numerosas inteligencias o “terrenos". La tetralogía cotidianías, ideologías, pan-ismos e ideoglobías se desenvuelve en sociedades complejas, donde se diferencian los ámbitos de existencia de las personas, en sus trabajos y preocupaciones.

Se destacan cinco trazos conclusivos: primero, las condiciones para caracterizar este tipo de expresiones eidéticas son (a) que se ocupe de la globalidad, aunque esta no siempre se entienda de modo completamente consensual; (b) que sea una propuesta normativa, para un mundo "mejor", para el planeta como conjunto; (c) que se plantee sobre la base de un diagnóstico y un programa, no solo de buenos deseos, diferenciándose así del género "utopía". A ello puede agregarse una condición respecto a su proceso de constitución: (d) que sea imaginada como (razonablemente) consensuable entre agentes de diversas nacionalidades, etnias, géneros, procedencias culturales y eidéticas en un mundo heterogéneo, (e) que venga siendo elaborada en la colaboración de múltiples agentes de lugares diversos, haciéndose eco de formulaciones suficientemente variadas para imaginar grandes espacios, procesos y consensos. Es decir, permitiendo un proceso de discusión con

\footnotetext{
${ }^{64}$ Yves Dezalay y Bryant G. Garth, La internacionalización de las luchas por el poder. La competencia entre abogados y economistas por transformar los Estados Latinoamericanos (Santiago de Chile: ILSA/Universidad Bolivariana, 2002).
} 
participantes de numerosos ecosistemas intelectuales del mundo, superando formulaciones demasiado apegadas a una parcialidad y que no harían sentido a la mayoría. Ello sin olvidar la tensión y el conflicto.

Segundo, las ideoglobías no son consensuales en el sentido de únicas o exclusivas, sino que operan en los debates sobre opciones respecto de un mundo mejor, de una convivencia global más armónica, justa y viable. Ninguna de las presentadas es vista como carente de limitaciones, siendo por ahora la más insalvable el origen de cada una dentro de una trayectoria eidética específica, cosa que la hace sospechosa o insignificante para otras trayectorias eidético-culturales y agentes sociales. ${ }^{65}$ Ello viene acompañado e imbricado con otra sospecha: representar los intereses de los "poderosos del Norte" o de los "revanchistas del Sur" o los intereses de una potencia o coalición, en desmedro de otra. La existencia de ideoglobías no supone la unanimidad y como cualquier otra expresión eidética se encuentra de hecho puesta en debate.

Tercero, el gobernancismo global es la ideoglobía prototípica en términos de la formulación, cumpliendo con muchos requisitos: criterios amplios, valores compartidos y protagonismo de organismos internacionales. Sin embargo, en otro plano, en la pluralidad de la agencia, el derechohumanismo y el ambientalismo cumplen mejor con los requisitos, pues vienen siendo alimentados por millones de agentes. En este plano, también fue muy variada la procedencia de voces que venían gestando y modelando el noeismo, como escasísimas las voces que viene alimentando el discurso del neotianxiaismo, que se encuentra en clara desventaja, por la carencia de contribuciones desde muchas culturas y Estados.

Cuarto, el derechohumanismo ha alcanzado la condición de ideoglobía que trasciende con mucho a quienes lo fueron originando y desenvolviendo. Se trata de una entidad eidética que ha tomado vida propia, por la dinámica de millones y millones de inteligencias en las cuales se encuentra alojada y que la alimentan. Esta entidad, o mejor este clúster eidético, ${ }^{66}$ va tomando múltiples formas, comunicándose y cruzándose con otras, mucho más allá de las voluntades o designios de las personas, y trabajando por colonizar nuevos espacios. Asimismo, como parte del mismo proceso, se va combinando

${ }^{65}$ Véase Ibidem.

${ }^{66}$ Sobre racimo o clúster eidético véase Devés, "Los estudios de las ideas". 
con otras entidades eidéticas de muy diversa procedencia (ecologismo, socialismo, feminismo, desarrollismo, indigenismo, animalismo) y manifestándose de maneras diversas (derechos de primera, segunda, tercera generación, derechos de los niños, derechos de los pueblos indígenas, derechos de la naturaleza, derechos de los animales, entre otras). No existe un "súpercerebro" que esté planificando este proceso. Se trata de un clúster, no siempre homogéneo e idéntico, alojado en millones de cerebros-mentes, operando en una dialéctica de contacto, sinergia y competencia con otras entidades eidéticas en multitud de ecosistemas intelectuales, con mucha inversión de energía propia, por parte de gente comprometida, como también con fondos de instituciones, que reclutan profesionales para impulsar sus ideas.

\section{Lineas de investigación a futuro}

La primera pista consiste en elaborar criterios más sólidos que permitan establecer el quiebre epistemológico entre los antecedentes acumulados y el momento en que estos cristalizan en ideoglobía, como una entidad eidética, con los atributos con que se ha definido la noción.

La segunda pista de investigación apunta hacia las posibilidades de compatibilizar una expresión eidética específica, aparecida y desarrollada en el seno de una trayectoria, con la necesaria pretensión global de este género de expresiones. Sin embargo, no es posible imaginar una expresión eidética, y por ello una globía, que no emerja en relación a alguna trayectoria eidético-cultural, como es también el caso de las otras que se han mencionado. Quizás, para alcanzar los grados necesarios de globalidad (o "universalidad") se hace necesaria la hibridación (o convergencia) de trayectorias, donde confluyan componentes significativos para algunas de las que poseen mayor masividad, además del trabajo conjunto de personas procedentes de variadas trayectorias y que coinciden en un proyecto.

La tercera pista de investigación sugerida se refiere a los modos para determinar las pruebas de su valor. Dicho de otra manera, trabajar sobre ideoglobías debe contemplar preguntas acerca del conjunto de factores que hagan verdaderamente factible una mejor convivencia global. Las ideoglobías adquieren mayor o menos valor, entre otras cosas, por su eficiencia para avanzar hacia dicho objetivo, de modo que su validez pasa a depender 
de los resultados obtenidos, aunque el proceso de "verificación/falseamiento" deriva de una hermenéutica notoriamente menos transparente que la del método científico.

La cuarta pista sugerida consiste en desarrollar mejor la noción "ideoglobía” con lo que se hace más patente la posibilidad y la capacidad de pensar globalmente. Ciertamente, la palabra no es imprescindible, pero contribuye a dar cuenta de este género de relatos. La propia dimensión o capacidad performativa de las lenguas, de hacer cosas con palabras, ${ }^{67}$ hace que la designación como "ideoglobía” le otorgue mayor prestancia y nitidez a esta expresión eidética en el marco de lo que se ha llamado el "paisaje eidético", ${ }^{68}$

\section{Bibliografía}

Alburquerque, Germán. “Tercermundismo en el Cono Sur de América Latina: ideología y sensibilidad. Argentina, Brasil, Chile y Uruguay, 1956-1990”. Tempo e Argumento, 6, núm. 13 (septiembre-diciembre 2014): 140-173. http://dx.doi.org/10.5965/2175180306132014140.

Amin, Samir. "Self-reliance and the New International Economic Order", Monthly Review, 29, núm. 3 (julio-agosto 1977): 1-21. https://doi.org/10.14452/MR-029-03-197707 1.

Austin, John. Cómo hacer cosas con palabra. Barcelona: Paidós, 1990.

Berisso, Lía, y Horacio Bernardo. Introducción al pensamiento uruguayo. Montevideo: Cruz del Sur, 2011.

Bhagwati, Jagdish N. (ed.), The New International Economic Order: The North-South Debate. Cambridge MA: The Massachusetts Institute of Technology Press, 1977.

Cerutti, Horacio. Hacia una metodología de la historia de las ideas (filosóficas) en América Latina. Jalisco: Universidad de Guadalajara, 1986.

Commission on Global Governance. Our Global Neighborhood. The Report of the Commission on Global Governance. Oxford: Oxford University Press, 1995.

\footnotetext{
${ }^{67}$ John Austin, Cómo hacer cosas con palabras (Barcelona, Paidós, 1990)

${ }^{68}$ Steger, "Political Ideologies". 
Corea, Gamani. Need for Change: Towards the New International Economic Order. Oxford: Pergamon Press, 1980.

Cox, Robert. "Ideologies and the New International Economic Order: Reflections on some recent literature”. International Organization, 33, núm. 2 (marzo-julio, 1979), 257 302. https://doi.org/10.1017/S0020818300032161.

Devés, Eduardo. "Direitos humanos, sociedade civil e gentecracia na esfera mundial: pensando a partir do sul”. En Daniel R. Cenci y Gilmar Bedin (org.) Direitos humanos, relaçoes internacionais e medio ambiente. Curitiba: Multimedia, 2013.

Devés, Eduardo. Pensamiento Periférico Asia-África-América Latina - Eurasia y algo más. Una tesis interpretativa global. Santiago de Chile: Ariadna, 2017.

Devés, Eduardo. "Los estudios de las ideas y las intelectualidades en América Latina a inicios del XXI: cartografía, trazos característicos y evaluación. Un ensayo con perspectiva personal. Primera parte: Cartografía de los estudios eidéticos”. Revista Wirapuru, núm. 1 (enero-junio, 2020): 100-111. http://doi.org/10.5281/zenodo.4289280.

Devés, Eduardo. "Redes teosóficas latinoamericanas y globales, 1875-1930: logias, sociedad civil, agentes internacionales. Cuestiones conceptuales y empíricas”, Revista Izquierdas, núm. 49 (octubre, 2020).

Devés, Eduardo. "Cotidianías” en América Latina actual: conceptos, géneros, contrastes, Estudios $\quad$ Avanzados, $\quad$ núm. $\quad 34 \quad$ (2021): 1-14. https://doi.org/10.35588/estudav.v0i34.4824

Devés, Eduardo, y Andrés Kozel. Estudios Eidéticos. Una conversación desde el sur, sobre la vida de las ideas y la reconfiguración de un espacio disciplinar. Santiago de Chile: Ariadna, 2018.

Devés, Eduardo, y César Ross. Las ciencias económico-sociales latinoamericanas en África Sudsahariana. Santiago de Chile: Ariadna, 2009.

Dezalay, Yves, y Garth Bryant. La internacionalización de las luchas por el poder. La competencia entre abogados y economistas por transformar los Estados Latinoamericanos. Santiago de Chile: ILSA/Universidad Bolivariana, 2002. 
Estenssoro, Fernando. Historia del debate ambiental en la política mundial 1945-1992 La Perspectiva Latinoamericana. Santiago de Chile: Instituto de Estudios Avanzados, Universidad de Santiago de Chile, 2014.

Estenssoro, Fernando, y Eduardo Devés. “Antecedentes históricos del debate ambiental global: Los primeros aportes latinoamericanos al origen del concepto de Medio Ambiente y Desarrollo (1970-1980)”. Estudos IberoAmericanos, 39, núm. 2 (juliodiciembre, 2013): 237-261.

Franchini, Matías, Eduardo Viola y Ana F. Barros-Platiau. "Los desafíos del antropoceno: de la política ambiental internacional hacia la gobernanza global”. Ambiente \& Sociedade São Paulo, 20, núm. 3 (julio-septiembre, 2017): 179-206. https://doi.org/10.1590/1809-4422asoc214v2022017.

Freeden Michael. Ideology: A Very Short Introduction. Oxford: Oxford University Press, 2003.

Galvis, Felipe A. "Samuel Moyn, La última utopía: los derechos humanos en la historia" Estudios Socio-Jurídicos, 19, núm. 1 (enero-junio 2017): 167-176.

Herrera, Amílcar. ¿Catástrofe o Nueva Sociedad? Modelo mundial latinoamericano. Bogotá: CIID, 1978.

Huntington, Samuel. La tercera ola democratizadora. La democratización a finales del siglo XX. Barcelona: Paidós Ibérica, 1994.

Huyghe, Bernard. "Cuando las ideas andaban a pie". El Correo de la Unesco, 50 (junio, 1997): 6-9.

Lafer, Celso. "Reflexiones sobre el tema del nuevo orden mundial en un orden internacional en transformación”, Estudios Internacionales, 15, núm. 58 (abriljunio, 1982): 127-165. https://doi.org/10.5354/0719-3769.2011.16047.

Lanfranco, Marina Laura. "Ambientalismo". En Hugo Biagini y Arturo Roig (dir.), Diccionario del Pensamiento Alternativo Tomo II. Buenos Aires: Biblos, 2008.

Legler, Thomas. "Gobernanza Global". En Thomas Legler, Arturo Santa Cruz y Laura Zamudio González (eds.), Introducción a las Relaciones Internacionales: América Latina y la Política Global. México: Oxford University Press, 2013.

López Barja de Quiroga, Pedro. Imperio legítimo: El pensamiento político en tiempos de Cicerón. Madrid: Antonio Machado Libros, 2007. 
Luque, Juan de Dios. Aspectos universales y particulares del léxico de las lenguas del mundo. Granada: Método, 2001.

Miró-Quesada, Francisco. Despertar y proyecto del filosofar latinoamericano. México: Fondo de Cultura Económica, 1974.

Moyn, Samuel. La última utopía: los derechos humanos en la historia. Bogotá: Universidad Javeriana, 2015.

Namer, Gérard. "La memoria, el tiempo y la historia en Karl Mannheim y en Maurice Halbwachs". Stvdia Histórica. Historia Antigua, núm. 25 (2007): 23-36.

Olmo, Rubén. "La idea imperial en Virgilio". Espacio, Tiempo y Forma. Serie II, Historia Antigua, núm. 21 (enero, 2008): 259-273, https://doi.org/10.5944/etfii.21.2008.1722.

Oteiza, Enrique, A. Rahman, R. Green, and C. Vaitsos. "Technical Co-operation among Developing Countries as a New Dimension of International Cooperation for Development. An Outline" United Nations. A/CONF. 79/PC/12 (1 de Julio 1977). Preparatory Committee for the UN Conference on Technical Cooperation among Developing Countries.

Prebisch, Raúl. "Cinco. etapas de mi pensamiento sobre el desarrollo". Comercio Exterior, 37, núm. 5 (mayo, 1987): 345-352.

Qin, Yaqing. "Cultura y pensamiento global: una teoría china de las relaciones internacionales". Revista CIDOB d'Afers Internacionals, núm. 100 (diciembre, 2012): 67-90.

Sassen, Saskia. A Sociology of Globalization. Nueva York: W.W. Norton, 2007.

Steger, Manfred B., "Political Ideologies and Social Imaginaries in the Global Age", Global justice: Theory practice rhetoric, núm. 2 (2009): 1-17. https://doi.org/10.21248/gjn.2.0.13.

Steger, Manfred B., y Paul James (eds.), Globalization and Culture. Volume IV, Ideologies of Globalism. Londres: Sage, 2010.

Trindade, Antonio, y Augusto Cançado. Tratado de Direito Internacional dos Direitos Humanos. Volume I. Porto Alegre: Sergio Antonio Fabris, 1997.

Tu Wei-Ming. "Asian Values and the Asian Crisis: A Confucian Humanist Perspective". En www.ruf.rice.edu/ tnchina/comentary/tu1098.html. 
UNCTAD. The History of UNCTAD. 1964-1984. Nueva York: United Nations, 1985.

Valdivielso, Joaquín. "La globalización del ecologismo. Del ecocentrismo a la justicia ambiental". Medio Ambiente y Comportamiento Humano, 6, núm. 2 (2005): 183204.

Villamar, Zirahuén, "Gobernanza Global y (su propio) desarrollo". Revista de Relaciones Internacionales de la UNAM, núm. 127 (enero-abril, 2017): 135-149.

Wendt, Alexander. "Why a World State is Inevitable" European Journal of International Relations, 9, núm. 4 (diciembre, 2003): 491-592. https://doi.org/10.1177/135406610394001.

Zea, Leopoldo. Historia del Pensamiento Latinoamericano. México: Editorial de la Universidad Autónoma de México, 1979.

Zhao Tingyang. A World without a Worldview: Political Philosophy and Cultural Philosophy. Guilin: Guangxi Normal University Press, 2005.

Zhao, Tingyang, "Rethinking Empire from a Chinese Concept "All-under-heaven", Social Identities, 12, Núm. 1 (enero, 2006): 29-41. https://doi.org/10.1080/13504630600555559.

Zhao Tingyang, The China Dream in question. Cambridge MA: Harvard-Yenching Institute Working Paper Series, 2013. 